\title{
Pelatihan Keselamatan Dan Kesehatan Kerja (K3) Bagi Pengelola Bank Sampah Berkah Abadi Kelurahan Limbungan
}

\author{
David Setiawan*1, Hamzah Eteruddin² $^{2}$ Ambar Tri Ratnaningsih ${ }^{3}$, Monice ${ }^{4}$ \\ 1,2,4Program Studi Teknik Elektro, Fakultas Teknik, Universitas Lancang Kuning \\ ${ }^{3}$ Program Studi Kehutanan, Fakultas Kehutanan, Universitas Lancang Kuning \\ e-mail: dsetia@unilak.ac.id ${ }^{1}$, hamzah@unilak.ac.id², ambar@unilak.ac.id ${ }^{3}$
}

\begin{abstract}
The Waste Bank is currently a solution in solving the waste problem, especially in the city of Pekanbaru, waste that has no economic value which has been the source of floods, pollution and disgusting dirt can be transformed into goods and other products that have high economic value. In its management, it is necessary to have occupational safety and health (K3) in the electricity sector so that the work equipment in the form of machines that are operated using electric power and its installation conforms to the applicable SOP standards, with the hope that zero accidents for safety and health in the workplace environment. Work Safety and Health (K3) Electricity Training for Waste Bank Managers of Limbungan Village aims to increase knowledge, handling and preventive steps that must be taken when unsafe uses and installations are found / which can threaten work safety or the threat of fire due to short circuit and so on. as well as prioritizing or prioritizing Occupational Safety and Health (K3) in general and in particular Electricity so that managers become educated on how Occupational Safety and Health (K3) especially Electricity can be carried out in daily activities and life both within the Waste Bank Kelurahan Limbungan and in other places.
\end{abstract}

Keywords: Waste Bank, K3 Electricity, Habits, Workplace Environment

\begin{abstract}
Abstrak
Bank Sampah saat ini menjadi solusi dalam memecahkan persoalan sampah terutama di Kota Pekanbaru, sampah yang tidak bernilai ekonomis yang selama ini menjadi penyebab kebanjiran, polusi serta kotoran yang menjijikkan dapat menjadi barang - barang dan produk lainnya yang memiliki nilai ekonomis yang tinggi. Dalam pengelolaannya, diperlukan Keselamatan dan Kesehatan Kerja (K3) bidang kelistrikan agar peralatan kerja berupa mesin yang dioperasikan menggunakan tenaga listrik serta instalasinya telah sesuai standar yang berlaku sehingga capaian zero accident untuk keselamatan dan kesehatan dilingkungan tempat kerja dapat terwujud. Pelatihan Keselamatan dan Kesehatan Kerja (K3) Kelistrikan bagi Pengelola Bank Sampah Kelurahan Limbungan bertujuan untuk menambah pengetahuan, cara penanganan, serta langkah preventif apa saja yang harus dilakukan agar penggunaan dan pemasangan yang tidak selamat (dapat mengancam keselamatan kerja, ancaman kebakaran akibat konsleting dan sebagainya) dapat dihindari sehingga pelatihan ini diharapkan dapat mengubah budaya hidup selamat dengan moto mengutamakan Keselamatan dan Kesehatan Kerja (K3) khususnya kelistrikan di lingkungan Bank Sampah Berkah Abadi Kelurahan Limbungan.
\end{abstract}

Kata kunci: Bank Sampah, K3 Kelistrikan, Kebiasaan, Lingkungan Kerja

\section{PENDAHULUAN}

Bank Sampah Kelurahan Limbungan pengelolaannya berada di RW.09 Kelurahan Limbungan, luas bangunan \pm 250 persegi. Telah banyak upaya yang dilakukan guna memilah, mengolah dan memproduksi sampah menjadi produk yang memiliki nilai ekonomis yang tinggi (Hikmah \& Ruing, 2020; Siswati, Ningsih, \& Eteruddin, 2020; Siswati, Rini Nizar, \& Anto Ariyanto, 2020). Dalam setahun terakhir, kegiatan pengelolaan sampah di Bank Sampah Kelurahan Limbungan agak sedikit menurun. Hal ini disebabkan oleh perubahan dari swakelola sampah menjadi bank sampah sehingga sampah rumah tangga di lingkungan RW.09 di tampung dan dipilah, sisanya baru dibuat tempat pembuang akhir sampah tidak lagi dilakukan akbat adanya kebijakan Perda nomor 08 tahun 2014 tentang pengelolaan sampah, sehingga Bank Sampah Berkah Abadi murni menerima sampah dari sampah yang ditabungan oleh warga di lingkungan Kelurahan Limbungan. 
Berkaitan dengan menurunnya kegiatan pengelolaan Bank Sampah, Alat Pelindung Diri (APD) yang telah tersediapun kadang sering sekali tidak digunakan sehingga terkesan belum tersentuhnya pengetahuan pengelola terhadap pentingnya mengutamakan Keselamatan dan Kesehatan Kerja (K3) dilingkungan Bank Sampah. Berdasarkan wawancara dan melihat langsung kegiatan pengelolaan di bank sampah saat tim melakukan survei, tim menilai perlu memberikan pelatihan Keselamatan dan Kesehatan Kerja (K3) dilingkungan Bank Sampah terutama keselamatan dari bahaya sengatan listrik dan kebakaran akibat konsleting dari sambungan kabel dari sumber listrik ke peralatan listrik yang digunakan seperti mesin pencuci, pencacah dan sebagainya serta penting menggunakan APD saat melakukan operasi dilingkungan Bank Sampah saat peralatan dioperasikan.

Berdasarkan uraian diatas, diharapkan pelatihan dan pendampingan yang diberikan mampu merubah prilaku pengelola Bank Sampah agar kebiasaan tidak memprioritaskan Keselamatan dan Kesehatan Kerja (K3) menjadi memprioritaskan Keselamatan dan Kesehatan Kerja (K3) dilingkungan operasional Bank Sampah Kelurahan Limbungan. Selain memprioritaskan Keselamatan dan Kesehatan Kerja (K3) secara umum, pengetahuan pengelola tentang memprioritaskan Keselamatan dan Kesehatan Kerja (K3) Kelistrikan sangat perlu menjadi perhatian karena mesin yang umumnya digerakkan oleh tenaga listrik harus ada standart dan SOP dalam penggunaannya agar Keselamatan dan Kesehatan Kerja (K3) khusunya Kelistrikan sangat diprioritaskan. Untuk mewujudkan hal itu, diperlukan sosialisasi dan pelatihan Keselamatan dan Kesehatan Kerja (K3) Kelistrikan di lingkungan Bank Sampah Kelurahan Limbungan.

\section{METODE}

Metode pelaksanaan yang digunakan dalam kegiatan ini adalah:

1. Sosialisasi Keselamatan dan Kesehatan Kerja (K3) Umum dan Kelistrikan

Pada sesi ini, tim memberikan informasi tentang Keselamatan dan Kesehatan Kerja (K3) secara umum dan kelistrikan secara khususnya terutama yang berkaitan operasional dilingkungan Bank Sampah.

2. Pelatihan Keselamatan dan Kesehatan Kerja (K3) Umum dan Kelistrikan

Setelah dilakukan sosialisasi, dilaksanakan pelatihan Keselamatan dan Kesehatan Kerja (K3)

Umum dan Kelistrikan kepada Pengelola dan Pihak-pihak yang terlibat dalam operasional pengelolaan Bank Sampah Kelurahan Limbungan

3. Evaluasi

Teknik evaluasi hasil kegiatan dilakukan dengan memberikan quisioner kepada pengelola dan masyarakat yang terlibat dalam operasional Bank Sampah serta testimoni terhadap dampak pelatihan yang diberikan.

\section{HASIL DAN PEMBAHASAN}

Setelah diberlakukannya new normal paska Pembatasan Skala Besar Besaran (-PSBB) akibat penyebaran pandemi covid-19, tim pengabdian kemudian melaksanakan Pelatihan Keselamatan dan Kesehatan Kerja (K3) Kelistrikan yang dilaksankan pada hari Sabtu, tanggal 18 Juli 2020 di Universitas Lancang Kuning dengan tetap mengikuti protokol kesehatan yaitu menggunakan masker dan membatasi peserta pelatihan agar panitia dapat menjaga jarak peserta pelatihan sebagai salah satu protokol kesehatan dimasa pandemi seperti saat ini. 

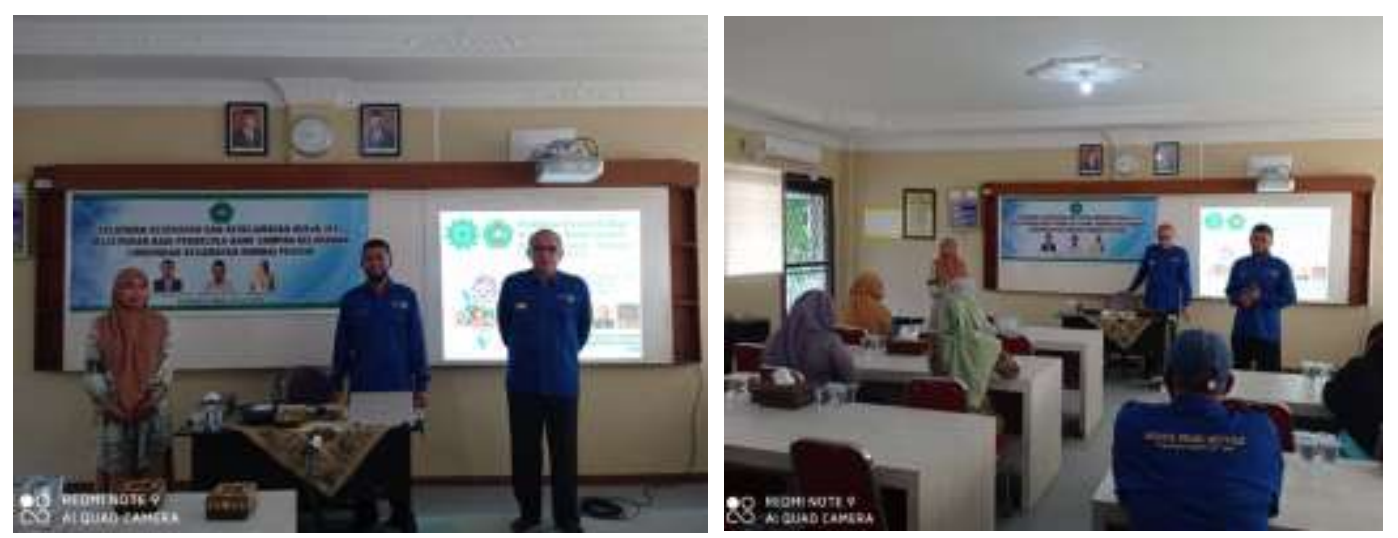

Gambar 1. Anggota tim pengabdian kepada Masyarakat

Pemateri adalah tim pengabdian itu sendiri, pemateri telah memiliki sertifikat K3 Kelistrikan serta aktif dalam kegiatan dan asosiasi tenaga listrik bahkan menjadi asesor ketenaga listrikan di beberapa asosiasi kelistrikan, sehingga pemateri dalam pelatihan ini sangat berpengalaman dalam bidang Keselamatan dan Kesehatan Kerja (K3) Kelistrikan.

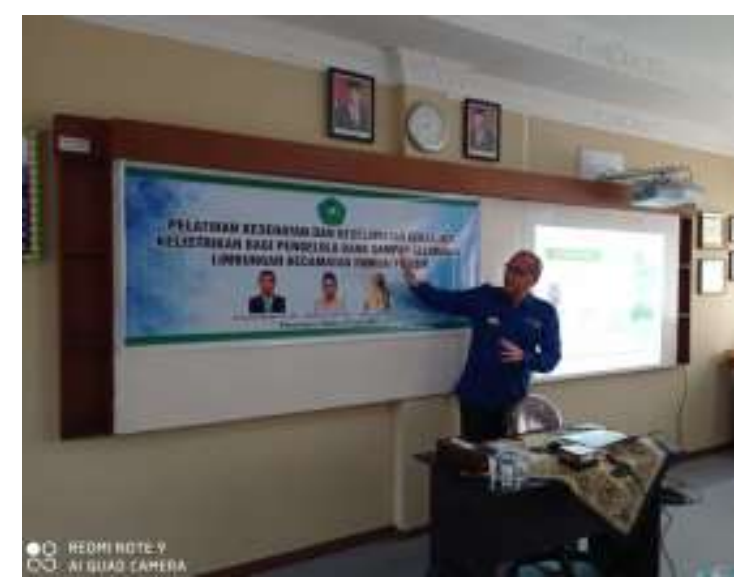

Gambar 2. Pamateri menjelaskan tujuan Pelatihan kepada Peserta

Walaupun dalam suasana pandemi, para peserta sangat antusias dan aktif dalam mengikuti pelatihan hal ini dibuktikan dengan banyaknya pertanyaan dan diskusi antara peserta dan pemateri tentang pengalaman pemateri terhadap pengalaman peserta baik pengalaman dalam pemanfaatan listrik dirumah maupun di Bank Sampah.

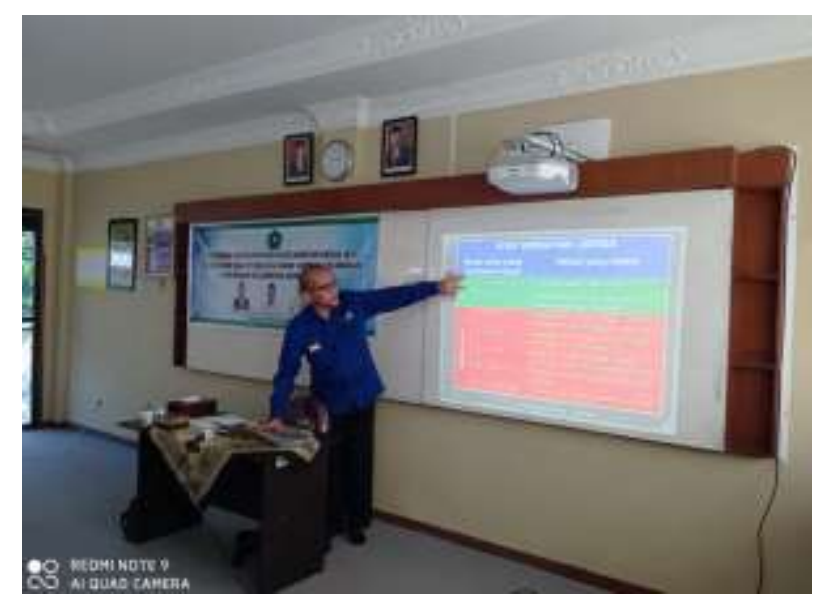

Gambar 3. Pameteri Mempresentasikan Dasar Hukum dan Bahaya Sengatan Listrik 


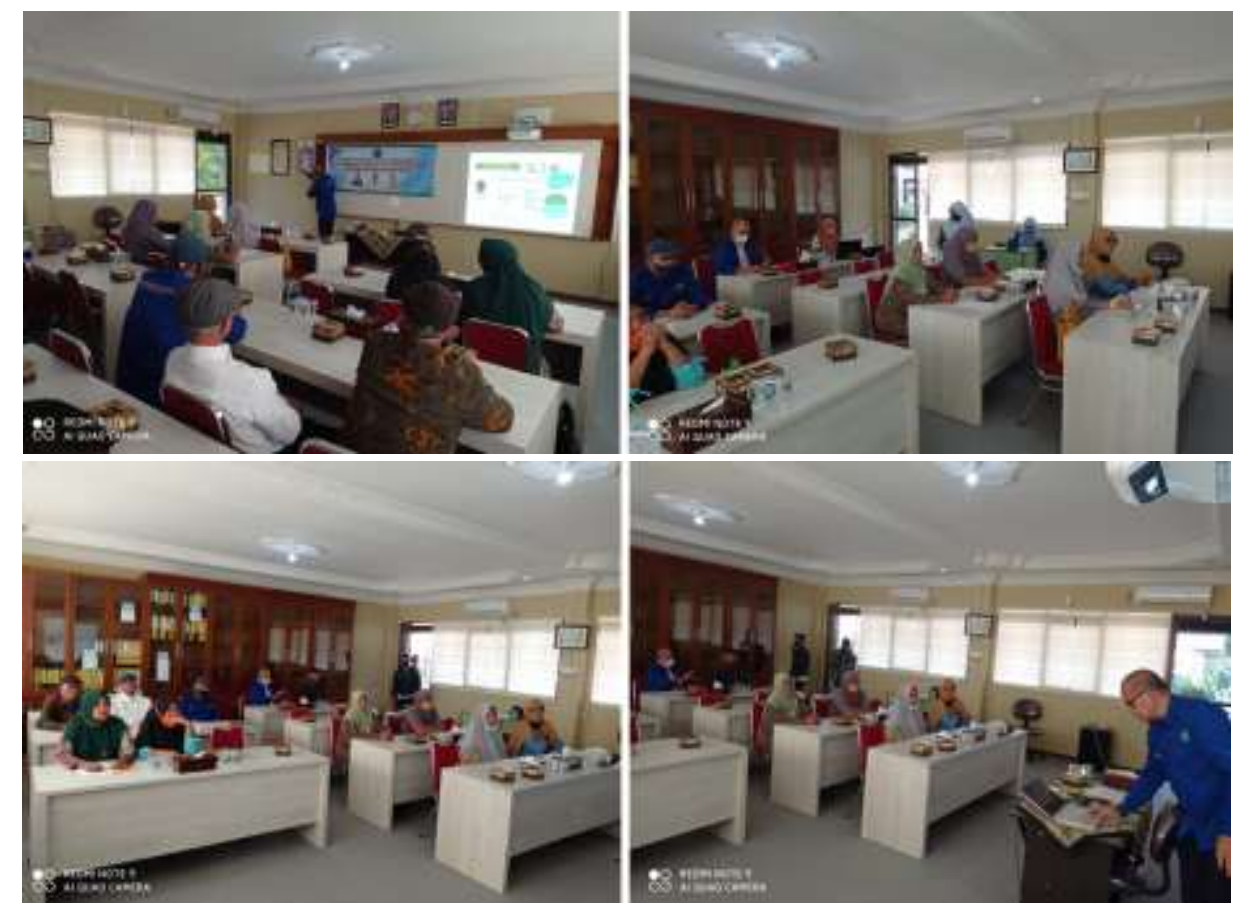

Gambar 4. Suasana pelatihan Pelatihan Keselamatan dan Kesehatan Kerja (K3) Kelistrikan

Setelah mendapatkan penerangan tentang manfaat listrik dan bahaya sengatan listrik serta penanggulangan atau penggunaan alat dan peralatan listrik yang sesuai dengan Persyaratan Umum Instalasi Listrik (PUIL). Penjelasan mengenai bahaya sengatan listrik juga telah diberikan pada beberapa tempat lainnya (Tanjung, Eteruddin, \& Setiawan, 2021; Tanjung, Zulfahri, \& Eteruddin, 2020; Tanjung, Zulfahri, Eteruddin, \& Setiawan, 2021). Diakhir pelatihan peserta diminta mengisi quisioner untuk mengukur pengetahuan peserta pada saat sebelum pelatihan dan setelah pelatihan serta penyerahan sertifikat pelatihan.

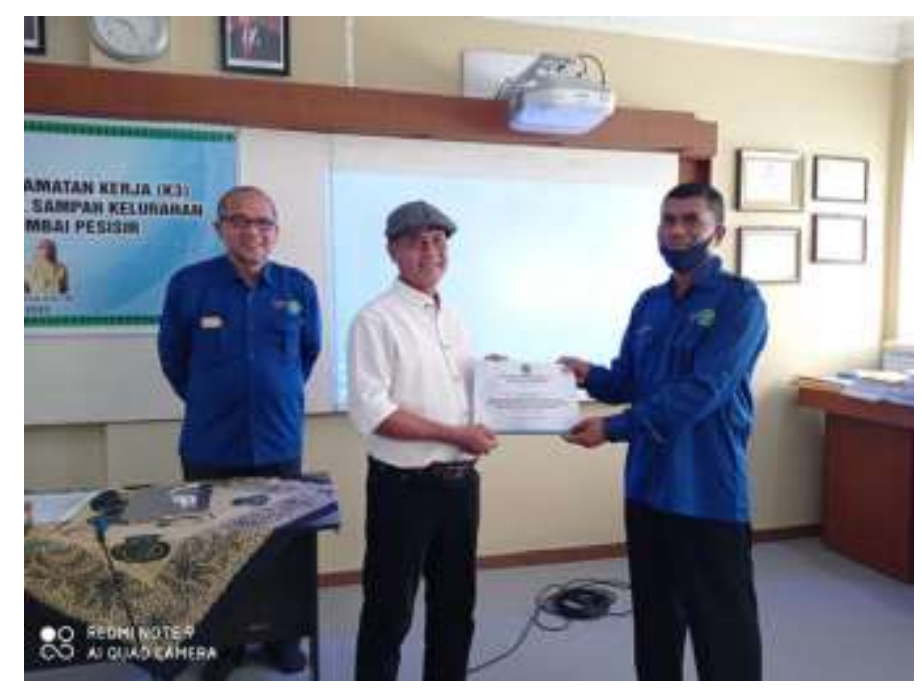

Gambar 5. Penyerahan Sertifikat Pelatihan kepada Ketua Bank Sampah Berkah Abadi 


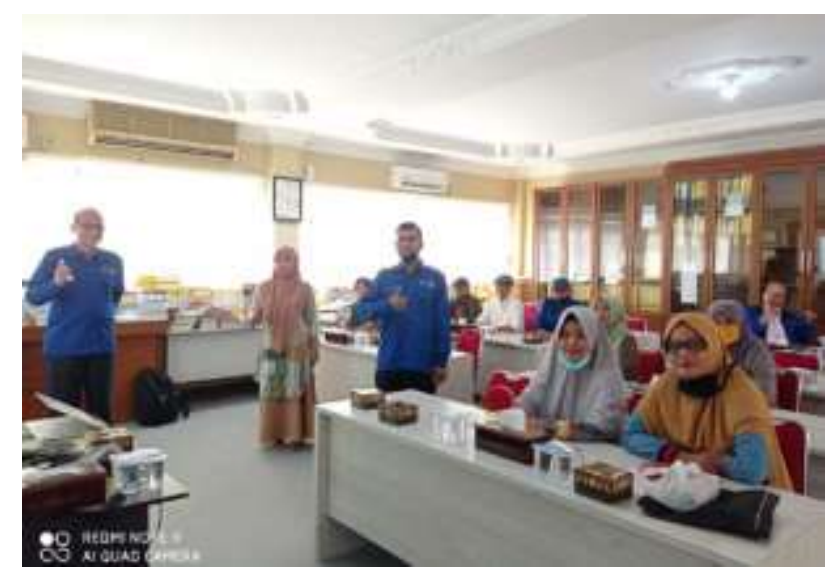

Gambar 6. Foto Bersama Tim dan Peserta Pelatihan

Setelah pelaksanaan pelatihan, data berupa isian quisioner yang diterima di olah dan dianalisis sebagai berikut :

Tabel 1. Penilaian Peserta Pelatihan Terhadap Pelaksanaan Pelatihan

\begin{tabular}{|c|c|c|c|c|c|c|c|c|c|c|c|c|c|c|c|c|c|c|c|c|}
\hline \multirow{2}{*}{ NO } & \multirow{2}{*}{ NAMA PESERTA } & \multicolumn{4}{|c|}{ FASILITAS } & \multicolumn{6}{|c|}{ MATERI } & \multicolumn{5}{|c|}{ INSTRUKTUR } & \multicolumn{3}{|c|}{ KEMANFAATAM } & \multirow{2}{*}{ RATA-RATA } \\
\hline & & 1 & 2 & 3 & 4 & 1 & 2 & 3 & 4 & 5 & 6 & 1 & 2 & 3 & 4 & 5 & 1 & 2 & 3 & \\
\hline 1 & HAYATI & 5 & 5 & 5 & 5 & 5 & 5 & 5 & 5 & 5 & 5 & 5 & 5 & 5 & 5 & 5 & 5 & 5 & 5 & 5,00 \\
\hline 2 & DESI PURWATI & 4 & 4 & 5 & 4 & 4 & 3 & 4 & 5 & 5 & 5 & 5 & 5 & 4 & 5 & 4 & 5 & 4 & 5 & 4,44 \\
\hline 3 & TFI WULANDARI & 4 & 4 & 4 & 4 & 4 & 4 & 4 & 4 & 4 & 4 & 5 & 4 & 5 & 4 & 4 & 4 & 4 & 4 & 4,11 \\
\hline 4 & WILDA OKTAVIA & 5 & 5 & 5 & 5 & 4 & 5 & 5 & 5 & 4 & 5 & 5 & 5 & 4 & 5 & 5 & 4 & 4 & 4 & 4,67 \\
\hline 5 & DARTINAH & 5 & 5 & 4 & 4 & 4 & 4 & 4 & 4 & 4 & 5 & 4 & 4 & 4 & 5 & 4 & 4 & 4 & 4 & 4,22 \\
\hline 6 & WIWIT JUITA & 5 & 3 & 5 & 5 & 5 & 5 & 4 & 5 & 4 & 5 & 5 & 5 & 5 & 5 & 5 & 3 & 5 & 5 & 4,67 \\
\hline 7 & ARI PURWANTO & 5 & 4 & 4 & 4 & 4 & 4 & 5 & 4 & 4 & 5 & 5 & 4 & 5 & 5 & 4 & 4 & 5 & 4 & 4,39 \\
\hline$B$ & IBNU HAJAR & 5 & 4 & 4 & 5 & 5 & 5 & 4 & 5 & 4 & 5 & 5 & 5 & 5 & 4 & 4 & 5 & 5 & 4 & 4,61 \\
\hline 9 & HASNAM SAID & 5 & 4 & 4 & 4 & 3 & 4 & 5 & 4 & 4 & 4 & 5 & 4 & 4 & 3 & 4 & 4 & 4 & 4 & 4,06 \\
\hline 10 & ULFA NUR ANIANI & 5 & 5 & 5 & 5 & 5 & 5 & 5 & 5 & 5 & 5 & 5 & 5 & 5 & 5 & 5 & 5 & 5 & 5 & 5,00 \\
\hline 11 & RUDI FAIZAL & 5 & 5 & 5 & 5 & 5 & 5 & 5 & 5 & 5 & 5 & 5 & 5 & 5 & 5 & 5 & 5 & 5 & 5 & 5,00 \\
\hline 12 & RIRIN FITALOKA & 5 & 5 & 5 & 5 & 5 & 5 & 5 & 5 & 5 & 5 & 5 & 5 & 5 & 5 & 5 & 5 & 5 & 5 & 5,00 \\
\hline 13 & DODI P. WARMAN & 5 & 3 & 4 & 5 & 4 & 4 & 4 & 4 & 4 & 5 & 5 & 4 & 4 & 4 & 4 & 4 & 4 & 5 & 4,22 \\
\hline 14 & DESI ARISTA & 4 & 3 & 4 & 4 & 4 & 4 & 4 & 4 & 4 & 4 & 4 & 4 & 4 & 4 & 4 & 4 & 4 & 4 & 3,94 \\
\hline 15 & BAYU ARI BOWO & 4 & 4 & 4 & 4 & 4 & 4 & 4 & 4 & 4 & 4 & 4 & 4 & 4 & 4 & 4 & 4 & 3 & 4 & 3,94 \\
\hline & RATA-RATA & 4,50 & 4,06 & 4,39 & 4,50 & 4,13 & 4,25 & 4,38 & 4,50 & 4,38 & 4,81 & 4,56 & 4,38 & 4,44 & 4,50 & 4,44 & 4,13 & 4,25 & 4,38 & \\
\hline
\end{tabular}

Berdasarkan pengetahuan sebelum pelatihan diberikan dan setelah pelatihan dilaksanakan, seluruh peserta setuju bahwa pelatihan yang diberikan sangat bermanfaat untuk merubah budaya selamat, menggunakan fasilitas berupa APD saat mengepoerasikan peralatan, materi yang mudah difahami dan sistematis serta instruktur yang jelas dan sesuai dengan bahan materi yang diberikan.

\section{KESIMPULAN}

Berdasarkan uraian diatas, penulis membuat kesimpulan tentang pelaksanaan Pelatihan Keselamatan dan Kesehatan Kerja (K3) Kelistrikan bagi Pengelola Bank Sampah Berkah Abadi, sebagai berikut :

1. Peserta sangat antusias mengikuti pelatihan yang dilaksanakan, hal ini terlihat dari antusiasnya peserta bertanya tentang pengalaman dan penyebab sengatan listrik bahkan potensi kebakaran akibat penggunaan alat listrik yang tidak standar

2. Peserta pelatihan belum mengetahui manfaat penggunaan kabel raun 3 konduktor (grounding/pembumian), selama ini para peserta menggunakan kabel raun 2 konduktor yang terhubung pada fasa dan netral saja dikarenakan harga yang lebih murah dan dan menganggap kabel yang terhubung ke grounding /Pembumian tidak penting.

3. Peserta tidak menyadari potensi kebakaran akibat sambungan yang tidak sempurna dalam penggunaan cok cabang (mendengarkan desisan pada cok cabang namun membiarkannya) 


\section{UCAPAN TERIMA KASIH}

Penulis mengucapkan terima kasih kepada Lembaga Penelitian dan Pengabdian kepada Masyarakan (LPPM) Universitas Lancang Kuning dan pimpinan Universitas Lancang Kuning yang telah mendanai dan memfasilitasi kegiatan ini sehingga Pelatihan Keselamatan dan Kesehatan Kerja (K3) Kelistrik dapat terlaksana dengan baik.

\section{DAFTAR PUSTAKA}

Azwar S. Sikap Manusia Teori dan Pengukurannya. Yogyakarta: Pustaka Pelajar; 2010.

Budiono S. Bunga Rampai Hiperkes dan Keselamatan Kerja. Semarang: Universitas Diponegoro; 2003.

Departemen Kesehatan Republik Indonesia. 2014 [cited 201720 Maret]. Available from: http://www.depkes.go.id/article/print/201411030005/1-orangpekerja-di-duniameninggal-setiap-15-detik-karenakecelakaankerja.html\#sthash.3hTidTq8.dpuf.

Hikmah, N., \& Ruing, H. L. (2020). Sosialisasi pembuatan bank sampah serta pengelolaan sampah organik serta anorganik. Masyarakat Berdaya Dan Inovasi, 1(2), 90-95. https://doi.org/10.33292/mayadani.v1i2.20

Jamsostek. Angka Kecelakaan Kerja Lima Tahun Terakhir Cenderung Naik 2011 [cited 201720 Maret]. Available from: http://www.poskotanews.com.

Menteri Ketenagakerjaan Republik Indonesia. Peraturan Menteri Ketenagakerjaan Republik Indonesia Nomor 10 Tahun 2016 Tentang Tata Cara Pemberian Program Kembali Kerja serta Kegiatan Promotif dan Kegiatan Preventif Kecelakaan Kerja dan Penyakit Akibat Kerja. Jakarta: Menteri Ketenagakerjaan Republik Indonesia; 2016.

Notoatmodjo S. Ilmu Perilaku Kesehatan. Jakarta: PT. Rineka Cipta; 2014.

Pratama AK. Hubungan Karakteristik Pekerja dengan Unsafe Action pada Tenaga Kerja Bongkar Muat di PT. Terminal Petikemas Surabaya. The Indonesian Journal of Occupational Safety and Health. 2015;4(1):64-73.

Santoso G. Manajemen Keselamatan dan Kesehatan Kerja. Jakarta: Prestasi Pustaka;2004.

Silalahi B. Manajemen Keselamatan dan Kesehatan Kerja. Jakarta: PT. Pustaka Binaman Pressindo; 1995.

Siswati, L., Ningsih, A. T. R., \& Eteruddin, H. (2020). Manfaatkan Sampah Rumah Tangga Menjadi Kompos di Kecamatan Minas Kabupten Siak. Prosiding Konferensi Nasional Pengabdian Kepada Masyarakat Dan Corporate Social Responsibility (PKM-CSR), 3, 498-504. https://doi.org/https://doi.org/10.37695/pkmcsr.v3i0.796

Siswati, L., Rini Nizar, \& Anto Ariyanto. (2020). Pengolahan Sampah Rumah Tangga Menjadi Kompos di Kelurahan Tuah Madani Kecamatan Tampan Kota Pekanbaru. Dinamisia : Jurnal $\begin{array}{lll}\text { Pengabdian Kepada } & \text { Masyarakat, 519-524. }\end{array}$ https://doi.org/10.31849/dinamisia.v4i3.4342

Suma'mur. Keselamatan Kerja dan Pencegahan Kecelakaan. Jakarta: CV. Haji Masagung; 1989.

Suma'mur. Higiene Perusahaan dan Kesehatan Kerja (Hiperkes). Bandung: Sagung Seto; 2014.

Tanjung, A., Eteruddin, H., \& Setiawan, D. (2021). Penerapan Persyaratan Umum Instalasi Listrik Dan Standarisasi Kelistrikan Di Kelurahan Maharani Kecamatan Rumbai. Fleksibel, 2(1), 3238. Retrieved from http://journal.unilak.ac.id/index.php/Fleksibel/article/view/6651

Tanjung, A., Zulfahri, Z., \& Eteruddin, H. (2020). Penggunaan Earth Leakage Circuit Breaker (ELCB) Dan Grounding Sebagai Pengaman Di Kelurahan Limbungan Baru Kecamatan Rumbai Pesisir. Fleksibel, 1(1), 7-13. $\quad$ Retrieved from http://journal.unilak.ac.id/index.php/Fleksibel/article/view/6051

Tanjung, A., Zulfahri, Z., Eteruddin, H., \& Setiawan, D. (2021). Penerapan Sistem Pengaman Instalasi Listrik di Kecamatan Rumbai Pesisir. Fleksibel, 1(2), 53-60. Retrieved from http://journal.unilak.ac.id/index.php/Fleksibel/article/view/6152

Tarwaka. Keselamatan dan Kesehatan Kerja : Manajemen dan Implementasi K3 di Tempat Kerja. Surakarta: Harapan Press; 2014.

Undang-Undang republik Indonesia Nomor 1 Tahun 1970 Tentang Keselamatan Kerja, (1970). 